\title{
Application of Magnetic Coconut Shell-derived Biocarbon for Methylene Blue Removal
}

\author{
Nor Asfaliza Abdullah ${ }^{1}$, Palsan Sannasi Abdullah', Mohamad Faiz Mohd Amin², Nor Azah \\ Zainol $^{3}$

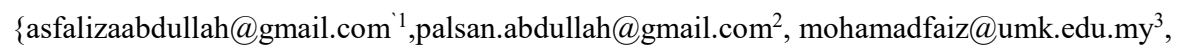 \\ azahzainol@kktmlenggong.edu.my ${ }^{4}$ \} \\ ${ }^{1}$ Faculty of Agro Based Industry, Universiti Malaysia Kelantan, Jeli Campus, 17600 Jeli, Kelantan, \\ Malaysia. \\ ${ }^{2}$ Faculty of Earth Science, University Malaysia Kelantan, Jeli Campus, 17600 Jeli, Kelantan, Malaysia. \\ ${ }^{3}$ MARA High Skill College, Mukim Durian Pipit, 33400 Lenggong, Perak, Malaysia.
}

\begin{abstract}
This study presents the preparation of magnetic biocarbon from coconut shell. The physicochemical properties of the prepared biocarbon was initially characterized by their iodine adsorptive capacity to estimate structure porosity and surface area. The comparative study was conducted between coconut shell-derived biocarbon (CSB), coconut shell-derived activated biocarbon (CSAB), and magnetic coconut shell-derived biocarbon (MCSB) to evaluate their adsorption efficiency towards methylene blue (MB) dyes in aqueous solution. The iodine number for CSAB showed greater difference compared to the CSB and MCSB. Meanwhile, the adsorption studies indicated that MCSB had higher adsorption value $(68.83 \mathrm{mg} / \mathrm{g})$ for methylene blue dye than the other biosorbents. This was due to abundant of $\mathrm{Fe}_{3} \mathrm{O}_{4}$ species and oxygen containing functional groups after the biocarbon was modified. The data of MB adsorption by MCSB reflected better adsorption efficiency overall. Hence, magnetization is suggested as a better option for biocarbon modification.
\end{abstract}

Keywords: Activated carbon, Coconut shell, Magnetic, Adsorption, Methylene blue.

\section{Introduction}

Malaysia is home to various types of industry such as agriculture, aquaculture, art and craft-based industry. Approximately, $70 \%$ of them are commonly function as small and medium entrepreneurs (SMEs), cottage and microenterprises (Akhir et al., 2015). Rearing activity of freshwater prawn, catfish, tilapia and other species generate income to the villagers while batik making along the east cost of Peninsular Malaysia (Kelantan, Terengganu and Pahang) has become a national identity of Malaysia. However, running these activities can make some disadvantages as well where fish farming produce nitrogen and phosphorus waste meanwhile batik making which involves process of dyeing fabric generate wax, resin, silicates and dye waste (Rashidi et al., 2013). Due to the recalcitrant nature of dyes and other chemicals, the release of effluent from batik industry will cause visible pollution because it interferes with light penetration resulting in reduced photosynthetic activity (Adegboyega et al., 2015). However, since both industry involves small scale entrepreneurs, there are no proper treatment is applied to treat their effluent.

Biocarbon is a bio-product with high carbon content. Generally, burning biomass e.g. wood, manure and leaves in a fire creates ash that enriched with minerals such as calcium, magnesium and inorganic carbonates. In contrast, biocarbon is produced when these biomass 
is heated in a closed container with little or no available oxygen is supplied (Saleh et al., 2016). The thermal decomposition of organic materials occuring within this stage developes internal pore structure with various sizes of micro-, meso- and macroporous. The increased porosity, higher surface area, as well as diverse functional groups e.i. carboxyl, hydroxyl, phenolic hydroxyl and carbonyl groups present on the surface make biocarbon a versatile material for numerous application like remediation of wastewater, fertilization of agriculture soils, renewable energy source and many more (Han et al., 2016).

Many methods are used for remediation of water contamination from organic as well as inorganic compounds in wastewater such as biological biodegradation (Al-Othman et al., 2013), coagulation, chemical oxidation, and froth floatation (Zargar, Parham and Rezazade, 2011). However, due to high operating costs, these methods are limitedly used especially in small to medium scale industries. The most common mechanism widely used today is adsorption because it is simple to operate (Saleh et al., 2016), low cost, uses less energy, less generation of toxic sludge, and higher removal efficiency (Mubarak et al., 2016). Adsorption is defined as a process of molecules etc. gases, solute or liquids (adsorbate) depositing onto the porous structure of the adsorbent. Usually, modern activated carbon (AC) is used as adsorbent to purify wastewater of industrial effluent (Bhatnagar et al., 2013). The used of AC as adsorbent in commercial systems is highly favourable but quite expensive due to the complex preparation and as materials are derived from non renewable sources of fossil fuel origin, i.e. bituminous coal, lignite, peat and petroleum coke which increase the production cost (Kamaruddin et al., 2013). Hence, many research had been conducted nowadays to find cheaper and more abundant source. Biocarbon derived from agricultural biomass is increasingly recognized as materials to replace AC due to high porosity, large surface area, and less expensive due to simpler production process (Mubarak et al., 2016). It is also reported that surface of the biocarbon is enriched with oxygen formed from various functional groups (Wang et al., 2017) and influences the adsorption behaviour in addition to their porous structure (Mubarak et al., 2016).

Even though agricultural biomass derived as biocarbon is an ideal absorbent due to lower cost but it faces the same difficulty as $\mathrm{AC}$ when separating from an aqueous solution as they are produced and used in powdered form. Therefore, modifying this biocarbon by loading magnetite, $\mathrm{Fe}_{3} \mathrm{O}_{4}$ particles will add magnetic effect to the adsorbent and making it easier to be separated using magnetic technique (Ruthiraan et al., 2014). The modification method of biocarbon have been studied extensively by different researchers for removal of heavy metals and other organic contaminants from wastewater like chromium (Han et al., 2014), cadmium (Ruthiraan et al., 2014), acid orange 7 dye (Wang et al., 2017) and 4-nitrotoluene (Saleh et al., 2016).

The goal of this present study is to prepare magnetic biocarbon material from coconut shell. Comparative kinetic studies of raw biocarbon, activated biocarbon and coconut shell based magnetic biocarbon had been carried out to determine the most efficient adsorbent to be employed for the removal of methylene blue dye in aqueous solution.

\section{Materials And Method}

\subsection{Adsorbent Preparation}

Coconut shell based biocarbon were obtained from local supplier, Green Impiana Brothers Solution (GIBS), at Melor, Kelantan. They were crushed and sieved to attain particle sizes of less than $150 \mu \mathrm{m}$ and labelled as CSB. Coconut shell activated biocarbon (CSAB) were prepared by using chemical activation; CSB was impregnated with sodium chloride 


$$
S_{B E T}=\left(\frac{I V \times 10^{-3}}{\text { Atomicmass of iodine }}\right) \times N_{A} \times \omega
$$

$(\mathrm{NaCl})$ as dehydrating agent at 1:1 ratio (wt/wt) overnight. The mixtures were introduced into the muffle furnace at specific temperature and holding time. After cooled down in furnace, they were extensively washed with distilled water until the $\mathrm{pH}$ became neutral. Finally, the samples were oven-dried at $105^{\circ} \mathrm{C}$ overnight. The samples were designated as CSAB. To prepare MCSB, CSB samples were added into the aqueous solutions of $\mathrm{FeCl}_{2}(2$ $\mathrm{M})$ and $\mathrm{FeCl}_{3}(1 \mathrm{M})$. Then, $\mathrm{NH}_{4}$ solution $(0.7 \mathrm{M})$ was added dropwise into the mixture under vigorous mechanical stirring. The resulting biocarbon (labelled as MCSB) were washed until the filtrate reached $\mathrm{pH} 7$ and dried in the oven at $110^{\circ} \mathrm{C}$ overnight. Finally, the samples were stored in a tightly closed container.

\subsection{Adsorbent Characterization}

The general properties of the samples such as biocarbon yield (\%) by mass, moisture content $(\%)$ by mass, ash content $(\%)$ by mass, $\mathrm{pH}$, and volatile matter were studied according to standard procedure (Anisuzzaman et al., 2015). Meanwhile, determination of iodine number was analysed according to ASTM prescribed method (ASTM, 2006).

\subsection{Solutions Preparation}

All reagents used were of analytical grade. A stock solution $(1000 \mathrm{mg} / \mathrm{L})$ was prepared from $\mathrm{MB}$ dye (molecular weight $=319.87 \mathrm{~g} / \mathrm{mol}$ ). Subsequent experimental solutions were prepared by diluting the stock solution with distilled water. The concentration of MB was determined at $660 \mathrm{~nm}$ by $\mathrm{UV}$-visible spectroscopy. Meanwhile, $0.1 \mathrm{~N}$ iodine solution was prepared by dissolving the sublimed iodine in the potassium iodide, and $0.05 \mathrm{~N}$ sodium thiosulphate was standardized with pure potassium iodide.

\subsection{Determination of iodine value}

A $40 \mathrm{ml}$ of standard iodine solution is treated with $0.2 \mathrm{~g}$ of carbon samples. The solution was shaken for $50 \mathrm{~min}$ and filtered after equilibrium. Ten $\mathrm{ml}$ of the filtrate is titrated with 0.05 $\mathrm{N}$ sodium thiosulphate solution, using starch as the indicator. Similarly, the quantity of thiosulphate to titrate $10 \mathrm{ml}$ of the blank solution was determined. Each titration was carried out in triplicates and the average titre used in calculating the iodine number (IV) using equation (Equation (1), (2), (3)) below:

$$
\begin{aligned}
& I V=C \times \text { Conversion factor }\left(C_{f}\right) \\
& C_{f}=\frac{\text { atomic mass of iodine } \times N \times 40}{w \times B} \\
& C=B-A
\end{aligned}
$$


where, atomic mass of iodine is $127, N$ is the normality of iodine solution used, $w$ is the mass of biocarbon used $(\mathrm{g}), 40$ is the volume $(\mathrm{ml})$ of thiosulphate for biocarbon free aliquot, and $B$ is the volume of thiosulphate for blank solution. Iodine number is calculated as the amount of iodine adsorbed (mg) by the biocarbon material $(\mathrm{g})$. Calculation of surface area based on iodine number is as follows (Equation (4)):

(4)

where, $I V$ is iodine number obtained in Equation (1), $N_{A}$ is $6.02 \times 10^{23} \mathrm{~mol}^{-1}$ and $\omega$ is $0.2096 \times 10^{-18}$.

\subsection{Adsorption of Methylene Blue}

In this assay, $0.025 \mathrm{~g}$ of biocarbon material is placed in contact with $25 \mathrm{ml}$ of a MB solution at different concentrations $(10,20,40,60,80$, and $100 \mathrm{mg} / \mathrm{L})$ for $24 \mathrm{~h}$ at room temperature. The remaining concentration after $24 \mathrm{~h}$ was analysed by UV-visible spectroscopy at $660 \mathrm{~nm}$. In this research, the amount of $\mathrm{MB}$ adsorbed in $\mathrm{mg} / \mathrm{g}$ from each solution is calculated as Equation (5) meanwhile adsorption efficiency (\% removal) is calculated according to Equation (6):

$$
\begin{aligned}
q_{e}(m g / g) & =\frac{\left(C_{\circ}-C_{e}\right) \times V}{m} \\
\backslash \quad \% \text { removal } & =\frac{\left(C_{\circ}-C_{e}\right)}{C_{\circ}} \times 100
\end{aligned}
$$

where, $C_{\text {。 }}$ is the initial concentration of $\mathrm{MB}$ solution in $\mathrm{mg} / \mathrm{L}, C_{e}$ is the concentration of MB solution at equilibrium time $(\mathrm{mg} / \mathrm{L}), V$ is the volume of solution treated in $\mathrm{L}$, and $m$ is the mass of adsorbent in $\mathrm{g}$.

\section{Results And Discussion}

Table 1 shows the result of proximate analysis conducted on sample biocarbon and activated biocarbon derived from coconut shell, known as CSB and CSAB respectively. The study was conducted according to American Society of Testing and Materials (ASTM, 2006). The fixed carbon content obtained from this study is higher than other biomass precursor reported before such as rice husk biocarbon (17.34\%) (Kizito et al., 2015), tamarind seed biocarbon (28.89\%) (Mopoung et al., 2015), and Leucaena leucocephala bark (18.10\%) (Anupam et al., 2011). This may be due to the structural compositional difference in terms of cellulose, hemicellulose and lignin that build up the cell wall of the precursor used (Hodgson et al., 2016). Hence, higher carbon content of coconut shell precursor may indicate suitability of this precursor as candidate for industrial waste water treatment application. The data also revealed that the fixed carbon content of CSAB is relatively higher than CSB. This could be attributed to the ability of $\mathrm{NaCl}$ to retain carbon and avoid loss of volatile matter. Thus, indicate the successful activation process by using of $\mathrm{NaCl}$ as dehydrating agent to replace other more corrosive chemicals reported before i.e. $\mathrm{H}_{3} \mathrm{PO}_{4}, \mathrm{H}_{2} \mathrm{SO}_{4}, \mathrm{ZnCl}, \mathrm{NaOH}$, and $\mathrm{KOH}$. $\mathrm{NaCl}$ may promote redistribution of carbon structure and increase the yield of fixed carbon. 
Table 1. Proximate analyses of coconut shell derived biocarbon and activated biocarbon.

\begin{tabular}{lcc}
\hline Sample & CSB & CSAB \\
\hline Ash content (\%) & 5.62 & 3.74 \\
\hline Moisture content (\%) & 6.27 & 3.24 \\
\hline Volatile matter (\%) & 46.92 & 31.25 \\
\hline Fixed carbon content (\%) & 41.19 & 61.17 \\
\hline $\mathrm{pH}$ & 7.25 & 7.78 \\
\hline
\end{tabular}

Iodine adsorption number or iodine number is one of the most important parameters to characterize carbon performance (Itodo et al., 2010). Iodine number is expressed in $\mathrm{mg} / \mathrm{g}$. It is also the measurement of micropore $(0-20 \AA)$ content of carbon samples by adsorption of iodine molecules from a solution. Iodine number is also depicted as an indication of total surface area. The typical range for iodine number required for waste water application is 500 $1200 \mathrm{mg} / \mathrm{g}$ (Mopoung et al., 2015).

Table 2. Iodine number and surface areas of CSB, CSAB, and MCSB.

\begin{tabular}{ccc}
\hline Sample & IV $(\mathrm{mg} / \mathrm{g})$ & Surface area $\left(\mathrm{m}^{2} / \mathrm{g}\right)$ \\
\hline CSB & 321.47 & 316.97 \\
\hline CSAB & 816.00 & 804.58 \\
\hline MCSB & 159.57 & 157.34 \\
\hline
\end{tabular}

The results of iodine number determination is shown in Table 2. It was revealed that $\mathrm{CSAB}$ has higher iodine number as compared to CSB. It is worth to mention here that simple pyrolysis produced biocarbon with limited porosities ( IV $=321.47 \mathrm{mg} / \mathrm{g}$ ) and smaller surface areas $\left(316.97 \mathrm{~m}^{2} / \mathrm{g}\right)$ whereas further treatment with salt $(\mathrm{NaCl})$ demonstrated higher porosities $(\mathrm{IV}=816.00 \mathrm{mg} / \mathrm{g})$ and larger surface area $\left(804.58 \mathrm{~m}^{2} / \mathrm{g}\right)$. Salts may have incorporated into the interior of the biocarbon and influenced development of internal porosity. Activation process also inhibits particle shrinkage and volume contraction (Guo et al., 2007). This result is in agreement with previous study where BET surface area of palm shells biocarbon (206 $\left.\mathrm{m}^{2} / \mathrm{g}\right)$ is lower than activated palm shells biocarbon treated with $\mathrm{H}_{2} \mathrm{SO}_{4}\left(1014 \mathrm{~m}^{2} / \mathrm{g}\right)(\mathrm{Guo}$ et al., 2005). On the other hand, MCSB gave lower iodine number $(159.57 \mathrm{mg} / \mathrm{g})$ compared to both CSB and CSAB. This may be due to the magnetic particles or magnetite $\left(\mathrm{Fe}_{3} \mathrm{O}_{4}\right)$ deposited onto the porous structure of the biocarbon hence the reduced iodine value (159.57 $\mathrm{mg} / \mathrm{g})$ with smaller surface area $\left(157.34 \mathrm{~m}^{2} / \mathrm{g}\right)$. This data was supported by the SEM-EDX analysis of magnetic sludge-derived biochar (MSDBC) conducted in the previous work where iron components was found distributed not only on the surface of biochar but also in the interior of MSDBC (Wang et al., 2017).

Figure 1 shows the effect of initial dye concentration (10 to $100 \mathrm{mg} / \mathrm{L}$ ) on MB adsorption capacity of CSB, CSAB, and MCSB. Equilibrium adsorption capacity $(\mathrm{mg} / \mathrm{g})$ increased with increase in $\mathrm{MB}$ initial concentration. The results suggested a high $\mathrm{MB}$ adsorption efficiency in all samples. It was observed that the adsorption capacity of CSAB was higher than CSB samples but lower than MCSB (CSB $<$ CSAB $<$ MCSB). The results supported the iodine value data where activated carbon material has a larger surface area and porosity compared to biocarbon coconut shell. From the results obtained it was revealed that when salt treatment is applied, the generation of internal porosity provide more sites for $\mathrm{MB}$ molecules to be adsorbed. 


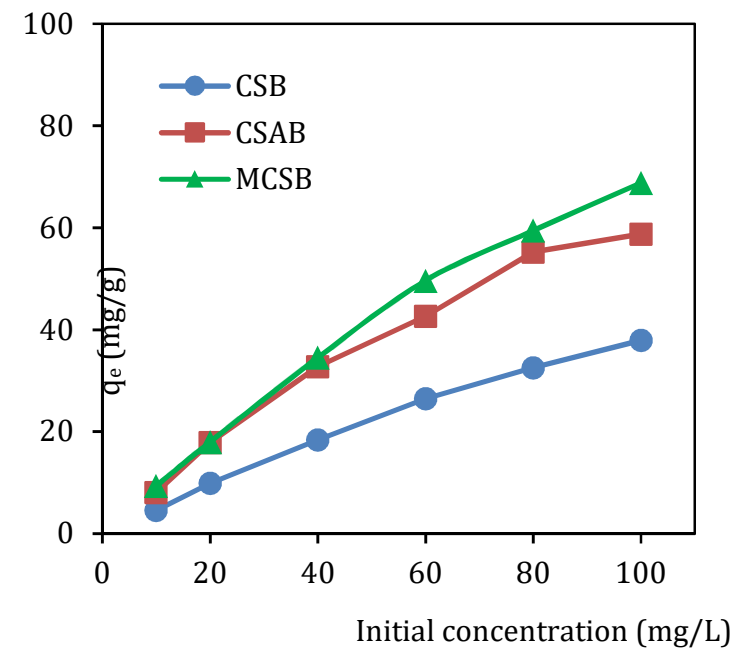

Fig.1. Effect of initial MB concentration onadsorption efficiency.

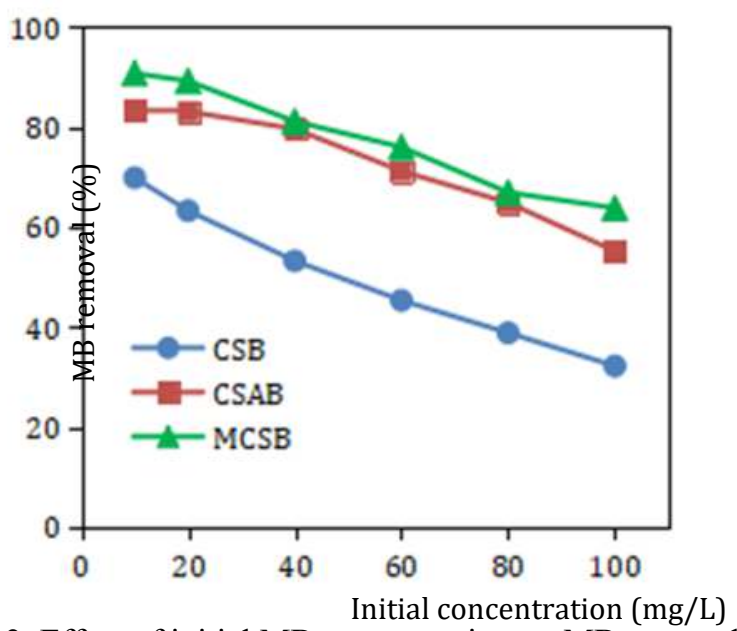

Fig.2. Effect of initial MB concentration on MB removal.

As shown in Figure 1, the data also demonstrated that loading magnetic $\mathrm{Fe}_{3} \mathrm{O}_{4}$ loading increased the adsorption efficiency of MCSB even albeit lower presence of porous structure (seen from lower iodine value). This may be due to abundant $\mathrm{Fe}_{3} \mathrm{O}_{4}$ particles and oxygen containing functional groups as biocarbon was modified. Drastic increase can be seen with qe $(\mathrm{mg} / \mathrm{g})$ under all initial concentration as both MCSB and CSB is compared. At initial concentration of $100 \mathrm{mg} / \mathrm{L}, \mathrm{MCSB}$ adsorbed $(68.83 \mathrm{mg} / \mathrm{g}) \mathrm{MB}$, higher than CSB $(37.94 \mathrm{mg} / \mathrm{g})$ and CSAB $(58.79 \mathrm{mg} / \mathrm{g})$. Similarly, at the same condition $(100 \mathrm{mg} / \mathrm{L}) \mathrm{MCSB}$ removed (63.78\%) more MB dye efficiently than CSB (32.24\%) and CSAB (55.18\%) as shown in Figure 2. The higher efficiency can be attributed to the combination of available porosity and due to the distribution of various functional groups that promoted chemical bonding reactions with the MB molecules within MCSB. 


\section{Conclusions}

This manuscript reports experimental data on physical characteristics of simple biocarbon pyrolysis and salt activated biocarbon (CSB and CSAB). The results clearly showed that both CSB and CSAB produced higher fixed carbon content, $41.19 \%$ and $61.17 \%$, respectively which makes it as potential candidates to treat batik manufacturing's effluent. In addition, high adsorption efficiency of CSAB (55.18\%) to remove MB dye from aqueous solution (100 $\mathrm{mg} / \mathrm{L})$ can be correlated to higher surface area $\left(804.58 \mathrm{~m}^{2} / \mathrm{g}\right)$. Meanwhile, the higher removal $(63.78 \%)$ using MCSB is most likely due to the abundance of $\mathrm{Fe}_{3} \mathrm{O}_{4}$ species and oxygen containing functional groups. Hence, magnetization of biocarbon samples can greatly increase adsorption capacity.

\section{Acknowledgemenrts}

The authors gratefully acknowledge the Ministry of Higher Education, Malaysia for supporting this study through the National Research Grant Scheme (R/NRGS/A07.00/00303A/002/2014/000151), the Faculty of Agro Based Industry and Faculty of Earth Science, Universiti Malaysia Kelantan, and to MARA High Skill College of Lenggong for use of the lab facilities. Also, to En. Khairil Azizi Ramli (MD of GIBS) for providing the carbonized coconut shells.

\section{References}

[1] Akhir, N. H. M. et al. 2015. Traditional Craftmanship: The Origin, Culture and Challenges of Batik Industry in Malaysia. Springer, Singapore.

[2] Adegboyega, S. O. et al. 2015. Preparation of phosphoric acid activated carbons from Canarium Schweinfurthii Nutshell and its role in methylene blue adsorption. Journal of Chemical Engineering and Materials Science, 6(2), pp. 9-14. doi: 10.5897/JCEMS2015.0219.

[3] Al-Othman, Z. A. et al. 2013. Kinetic and Thermodynamic Studies for Methylene Blue Adsorption using Activated Carbon Prepared from Agricultural and Municipal Solid Wastes. Asian Journal of Chemistry, 25, pp. 8301-8306.

[4] Anisuzzaman, S. M. et al. 2015. Preparation and characterization of activated carbon from Typha orientalis leaves. International Journal of Industrial Chemistry, 6(1), pp. 9-21. doi: 10.1007/s40090-014-0027-3.

[5] Anupam, K. et al. 2011. Adsorptive removal of chromium (VI) from aqueous solution over powdered activated carbon: Optimisation through response surface methodology. Chemical Engineering Journal. Elsevier B.V., 173(1), pp. 135-143. doi: 10.1016/j.cej.2011.07.049.

[6] ASTM, 2006. Standard Test Method for Determination of Iodine Number of Activated Carbon 1. ASTM International, 94(Reapproved), pp. 1-5. doi: 10.1520/D4607-14.2.

[7] Bhatnagar, A. et al. 2013. An overview of the modification methods of activated carbon for its water treatment application. Chemical Engineering Journal, 219(March 2013), pp. 499-511. doi: 10.1016/j.cej.2012.12.038.

[8] Guo, J. et al. 2005. Adsorption of $\mathrm{NH}_{3}$ onto activated carbon prepared from palm shells impregnated with $\mathrm{H}_{2} \mathrm{SO}_{4}$.Journal of Colloid and Interface Science, 281(2), pp. 285290. doi: $10.1016 /$ j.jcis.2004.08.101.

[9] Guo, W. S. et al. 2007. Experimental investigation of adsorption - flocculation microfiltration hybrid system in wastewater reuse. 242(2004), pp. 27-35. doi: 
10.1016/j.memsci.2003.06.006.

[10] Han, Y. et al. 2016. Adsorption kinetics of magnetic biochar derived from peanut hull on removal of $\mathrm{Cr}$ (VI) from aqueous solution: Effects of production conditions and particle size. Chemosphere. Elsevier Ltd, 145(February), pp. 336-341. doi: 10.1016/j.chemosphere.2015.11.050.

[11] Hodgson, E. et al. 2016. Optimisation of slow-pyrolysis process conditions to maximise char yield and heavy metal adsorption of biochar produced from different feedstocks. Bioresource Technology, 214, pp. 574-581. doi: 10.1016/j.biortech.2016.05.009.

[12] Itodo, U. et al. 2010. Application of Methylene Blue and Iodine Adsorption in the Measurement of Specific Surface Area by four Acid and Salt Treated Activated Carbons. New York Science Journal, 3(5), pp. 25-33.

[13] Kamaruddin, M. A. et al. 2013. Recent Developments of Textile Waste Water Treatment by Adsorption Process: A Review. International Journal of Scientific Research in Knowledge, (January 2017), pp. 60-73. doi: 10.12983/ijsrk-2013-p060073.

[14] Kizito, S. et al. 2015. Evaluation of slow pyrolyzed wood and rice husks biochar for adsorption of ammonium nitrogen from piggery manure anaerobic digestate slurry. Science of the Total Environment. Elsevier B.V., 505(October 2014), pp. 102-112. doi: 10.1016/j.scitotenv.2014.09.096.

[15] Mopoung, S. et al. 2015. Characterization and Properties of Activated Carbon Prepared from Tamarind Seeds by KOH Activation for Fe(III) Adsorption from Aqueous Solution. Scientific World Journal. Hindawi Publishing Corporation, 2015. doi: $10.1155 / 2015 / 415961$.

[16] Mubarak, N. et al. 2016. Comparative Kinetic Study of Removal of $\mathrm{Pb}^{2+}$ Ions and $\mathrm{Cr}^{3+}$ Ions from Waste Water using Carbon Nanotubes Produced using Microwave Heating. Carbon, 2(1), pp. 7. doi: 10.3390/c2010007.

[17] Rashidi, H. R. et al. 2013. Simulated Textile (Batik) Wastewater Pre-Treatment Through Application of a Baffle Separation Tank. Advanced Materials Research, 627, pp. 94-398.

[18] Ruthiraan, M. et al. 2014. Comparative Kinetic Study of Functionalized Carbon Nanotubes and Magnetic Biochar for Removal of $\mathrm{Cd}^{2+}$ Ions from Wastewater. Korean Journal of Chemical Engineering, 32(3), pp. 446-457.

[19] Saleh, S. et al. 2016. Removal of Organic Contaminant from Aqueous Solution Using Magnetic Biochar. Procedia Engineering. The Author(s), 148, pp. 228-235. doi: 10.1016/j.proeng.2016.06.590.

[20] Wang, J. et al. 2017. One-step Preparation and Application of Magnetic Sludge-derived Biochar on Acid Orange 7 Removal Via Both Adsorption and Persulfate Based Oxidation. The Royal Society of Chemistry Advances, 7, pp. 18696-18706.

[21] Zargar, B., Parham, H. and Rezazade, M. 2011. Fast removal and Recovery of Methylene Blue by Activated Carbon Modified with Magnetic Iron Oxide Nanoparticles. Journal of Chromatography A, 58(4), pp. 1-6. 